\title{
Jiři Koralka
}

\section{Das Deutsche Reich im tschechischen und slowakischen Urteil}

Das Verhältnis zum Deutschen Reich von 1871 bildete bis in den Zweiten Weltkrieg hinein immer nur einen Teil der Beziehungen der Tschechen zu den Deutschen. Das betraf auch alle tschechischen Einschätzungen der reichsdeutschen Politik und das tschechische Bild von der gesellschaftlichen und kulturellen Öffentlichkeit Deutschlands. Vom Norden, Westen und Süden war das tschechische Siedlungsgebiet von deutschsprachigen Territorien umklammert, man war sich der zahlenmäßigen, machtpolitischen und wirtschaftlichen Überlegenheit Deutschlands bewußt, aber für das Alltagsleben der tschechischen Gesellschaft schien das Verhältnis zu mehr als einem Drittel der deutschsprachigen Bewohner Böhmens und zu etwa einem Viertel der deutschsprachigen Bewohner Mährens viel wichtiger zu sein.

Unter diesen Verhältnissen war die politische und kulturelle Repräsentation der Tschechen in der österreichisch-ungarischen Vielvölkermonarchie immer bemüht, Idee und Wirklichkeit eines großdeutschen Staates, und zwar in jeder Form, als geradezu lebensgefährlich für die tschechische nationale Existenz hinzustellen und zu bekämpfen. In den Ländern der böhmischen Krone selbst konnten sich die Tschechen als die Mehrheitsnation fühlen und nach 1883 in Böhmen und nach 1905 in Mähren auch behaupten, aber in jedem größeren Staatsgebilde, das neben den österreichischen Erblāndern auch Nord- und Süddeutschland umfaßt hätte, wären die Tschechen nur eine nationale Minderheit kleineren Umfangs gewesen ${ }^{1}$. Aus geopolitischen Gründen war somit allen Tschechen klar, daß derjenige, der Wien mit Deutschland verbinden würde, niemals für längere Zeit bereit wãre, auf Böhmen und Mähren als wichtige Verbindungsländer zwischen Preußen, Sachsen, Bayern, Ober- und Niederösterreich zu verzichten.

Angesichts der exponierten Lage der böhmischen Länder bemühten sich alle vorsichtigeren tschechischen Politiker so weit wie möglich um eine weitgehende Minimalisierung des für die Tschechen lebenswichtigen deutschen Problems. Sie wollten unter anderem den Umstand nutzen, daß die Deutschen in Mitteleuropa staatspolitisch, konfessionell, kulturell und gefühlsmäßig keine Einheit bildeten. So versuchte

${ }^{1} \mathrm{Zu}$ diesem wandelbaren Mehrheits-Minderheits-Verhältnis vgl. ausführlich Jiř́ Koŕalka, Tschechen im Habsburgerreich und in Europa 1815-1914. Sozialgeschichtliche Zusammenhānge der neuzeitlichen Nationsbildung und der Nationalitātenfrage in den böhmischen Ländem (Schriftenreihe des Österreichischen Ost- und Südosteuropa-Instituts 18, Wien, München 1991) 133-138. 
die politische und intellektuelle Führungsschicht der Tschechen, eine differenzierte Haltung zu der sie umkreisenden deutschen Übermacht einzunehmen:

1. Es wurden tschechischerseits wiederholt Versuche unternommen, die wirtschaftlich und verkehrsmäßig mit dem tschechischen Binnenland eng verbundenen Deutschen in Böhmen und Mähren für die Idee eines gemeinsamen zweisprachigen, nach tschechischer Auffassung allerdings von den Tschechen geführten, böhmischen Staates zu gewinnen. Dieser Plan war durch den Umstand begünstigt, daß die Deutschen in Böhmen, Mähren und Österreichisch-Schlesien - von 1902 an gelegentlich, seit den 1920er Jahren regelmäßig als Sudetendeutsche bezeichnet - zwar viele Stammesund Regionalunterschiede aufwiesen, aber ihrer Mentalität, ihrer politischen Erfahrung und ihrer weitgehend staatsfeindlichen Einstellung nach sich von den Deutschen in Preußen, Sachsen und Bayern und zum Teil sogar auch von der Bevölkerung der österreichischen Donau- und Alpenländer unterschieden.

2. In gewissem Sinne konnten die Tschechen die durch die Kaiserstadt Wien symbolisierte, in sprachlicher Hinsicht deutsche Staatsführung des Kaisertums Österreich als Beschützer der tschechischen nationalen Existenz und Eigenständigkeit betrachten. Nachdem die verlorenen Kriege von 1859 und 1866 die Rückkehr zu einer einheitlichen, deutsch geführten österreichischen Gesamtmonarchie unmöglich gemacht hatten ${ }^{2}$, bildeten sich, zumindest im nichtungarischen Teil der habsburgischen Doppelmonarchie für den Aufstieg einer Reihe moderner Nationalgesellschaften günstige politische und rechtliche Bedingungen heraus ${ }^{3}$, darunter in erster Linie der Tschechen, Polen und Slowenen. In der Anerkennung der nationalen Eigenständigkeit und Selbstverwaltung der einzelnen Völker in einer multinationalen Föderation sahen die meisten tschechischen Politiker bis 1914 (zum Teil auch noch im Ersten Weltkrieg) den Hauptinhalt einer modernen österreichischen Staatsidee ${ }^{4}$.

3. In einigen Fällen konnten die Tschechen eine wohlwollende Neutralität, sogar eine Unterstützung von Vertretern der geographisch entfernten Bevölkerung Nord-, West- und Südwestdeutschlands erwarten, die im Nationalitätenkampf innerhalb Österreich-Ungarns nicht direkt engagiert waren. Wo es sich nicht um erstrangige machtpolitische Probleme handelte, sondern um gemeinsame Angelegenheiten des modernen Lebens, zum Beispiel im Städtebau, in der Gemeindeselbstverwaltung, in der bildenden Kunst oder im Sport, setzten die Tschechen mit einigem Recht voraus, daß sie in Berlin, Hamburg, Bremen, Köln, Frankfurt am Main, München oder Kon-

2 Die erste erfolgreiche Bresche in die supraethnische Konzeption des Kaisertums Österreich schlug die ungarische staatsrechtlich-nationale Opposition. Vgl. Robert A. Kann, The AustroHungarian Compromise of 1867 in Retrospect. Causes and Effect, in: Der österreichisch-ungarische Ausgleich 1867. Materialien (Referate und Diskussion) der internationalen Konferenz in Bratislava 28.8.-1.9. 1967, hrsg. von L'udovít Holotík und Anton Vantucb (Bratislava 1971) 2444.

3 Den Begriff der ,staatsoppositionellen Nationalgesellschaft“ prägte Theodor Schieder, Das deutsche Kaiserreich von 1871 als Nationalstaat (Wissenschaftliche Abhandlungen der Arbeitsgemeinschaft für Forschung des Landes Nordrhein-Westfalen 20, Köln, Opladen 1961) 8.

4 Vor allem Franz Palacký, Österreichs Staatsidee (Prag 1866); Josef Pekaŕ, Kdo založil Rakousko? [Wer hat Österreich begründet?], Neudruck in: ders., Na cestě k samostatnosti [Auf dem Weg zur Selbständigkeit] (Praha 1993) 35-39. 
stanz für ihr Bemühen, auf der europäischen Bühne als gleichberechtigter Partner akzeptiert zu werden, ein größeres Verstāndnis finden würden als in Wien, Eger (Cheb) oder Reichenberg (Liberec) ${ }^{5}$. Es kam noch als wichtiger Umstand dazu, daß die Tschechen mit den Deutschen im Reich bis 1938/39 niemals in einem gemeinsamen Staat lebten. Die Beziehung der Tschechen zu den außerösterreichischen Deutschen war also immer ein Verhältnis zum Ausland, wenn auch die Staatsgrenzen während des 19. Jahrhunderts bis hin zum Ersten Weltkrieg fast kein Hindernis für die Arbeitsmigration und das Reisen darstellten.

Die traditionelle katholisch-prohabsburgische Angst vor einem preußischen Eroberer, der der böhmischen Krone in der Mitte des 18. Jahrhunderts fast ganz Schlesien geraubt hatte ${ }^{6}$, und der auch im preußisch-österreichischen Krieg von 1866 die Integrität der Länder der böhmischen Krone nicht sonderlich achtete ${ }^{7}$, lebte in der tschechischen Gesellschaft in den letzten drei Jahrzehnten des 19. Jahrhunderts weiter fort. Es gab allerdings auch andere Traditionen im Verhältnis der Tschechen zu Nord- und Westdeutschland. Die tschechischsprachigen Böhmen nahmen nach den französischen Hugenotten den zweitwichtigsten Platz unter den religiösen Flüchtlingen und Einwanderern im Berliner Raum ein ${ }^{8}$. Unter tschechischen Gelehrten und Wirtschaftspublizisten war bereits vor dem Jahr 1871 eine klare, wenn auch meist zurückhaltende Bewunderung des norddeutsch-protestantischen Geistes- und Industrielebens spürbar'. Die führende Persönlichkeit der tschechischen Nationalbewegung um die Mitte des 19. Jahrhunderts, der Geschichtsforscher František Palacký (1798-1876), unterhielt rege Kontakte mit vielen nord- und westdeutschen Historikern und ließ auch seinen Sohn Jan Palacký (1830-1908) das Fach Geographie an der Berliner Universität studieren ${ }^{10}$. Den liberal und demokratisch eingestellten Besuchern aus Böhmen schien es, als könnten sie außerhalb Österreichs eine freiere Luft atmen. Eine wesentliche Rolle spielte dabei der Umstand, daß in keinem anderen Land (außer Böhmen) dem großen tschechischen Kirchenreformator Jan Hus (hingerichtet 1415) so viel wohlwollende Aufmerksamkeit zuteil wurde wie in Deutschland ${ }^{11}$.

Mit Rücksicht darauf, daß die tschechischen Politiker schon immer Österreich von Deutschland zu trennen wünschten, wurde die Auflösung des Deutschen Bundes von

5 Im breiteren Zusammenhang vgl. Jiři Koralka, Zwischen Angst und Vorbild. Das Deutsche Reich 1871-1914 aus der Sicht tschechischer Politiker, Besucher, Studenten und Gastarbeiter (Vorträge im Georg-Eckert-Institut, Braunschweig 1993).

6 František A. Slavík, Pruské usilování o země české [Preußische Anstrengungen um die böhmischen Lānder], in: Osvěta 18 (Praha 1888) 861-877, 1015-1028, 1075-1090.

7 Vgl. Otto Urban, Vzpomínka na Hradec Králové. Drama roku 1866 [Erinnerung an Königgrätz. Drama des Jahres 1866] (Praha 1986) 68-70, 82-83.

- Manfred Motel, Das Böhmische Dorf in Berlin. Die Geschichte eines Phänomens (Berlin 1983); Das Böhmische Dorf in Berlin-Neukölln 1737-1987. Dem Kelch zuliebe Exulant, hrsg. von Werner Korthaase (Stätten der Geschichte Berlins 20, Berlin 1987).

9 Vl. (Jilji Vratislav Jabn und František Ladislav Rieger), Berlín [Berlin], in: Slovník naučný [Konversationslexikon] 1 (Praha 1860) 644.

${ }^{10} J$ Jř́ Koŕalka, Palacký, Sybel a počátky Historische Zeitschrift [Palacký, Sybel und die Anfãnge der Historischen Zeitschrift], in: Husitský Tábor 9 (1986-1987) 199-248, hier: 217-219.

"Vgl. Jiři Koralka, Jan Hus und die Hussiten in den deutsch-tschechischen Beziehungen des 19. Jahrhunderts, in: Geschichte in Wissenschaft und Unterricht 35 (1984) 495-507. 
ihnen eindeutig positiv bewertet. Der preußische Kriegslärm und Siegesrausch nach der Schlacht bei Sedan wurde in tschechischen Zeitungen mit unverhohlener Antipathie kommentiert ${ }^{12}$, aber die bemerkenswerte Denkschrift der 86 tschechischen Abgeordneten des böhmischen Landtags zur auswärtigen Politik vom 8. Dezember 1870 stellte ausdrücklich fest: „Die böhmische Nation anerkennt konsequent die Vollberechtigung der verschiedenen Stämme der großen deutschen Nation, sich zu einer staatsrechtlichen Einheit zusammenzutun, soweit sie das Bedürfnis dazu fühlen. (...) Die deutsche Nation hat ein unzweifelhaftes Recht, Angriffe gegen ihr Gebiet oder gegen die Freiheit ihrer Selbstbestimmung in bezug auf ihre staatsrechtliche Einigung mit Waffengewalt zurückzuweisen. Sollte jedoch ihr Wille darauf gerichtet sein, der französischen Nation eine bestimmte Regierungsform aufzudrängen, oder ihr mit Gewalt Gebietsteile zu entreißen, deren Bevölkerungen sich als Franzosen fühlen und Franzosen bleiben wollen, so wäre sie im Begriffe, das Selbstbestimmungsrecht der betreffenden Volksstämme zu verletzen und Gewalt vor Recht zu setzen." ${ }^{\text {"13 }}$

Die Redewendung „La force prime le droit“ (Macht geht vor Recht) wurde in tschechischen politischen Kommentaren zur deutschen Reichsgründung nicht nur im $\mathrm{Zu}$ sammenhang mit der Annexion Elsaß-Lothringens mehrmals wiederholt und moralisch abgelehnt ${ }^{14}$. František Palacký machte in den politischen Schriften seiner letzten Lebensjahre auf den großen Unterschied zwischen der deutschen humanistischen Tradition der Vergangenheit und der gewalttätigen Politik der Gegenwart aufmerksam. In dem am 4. Mai 1874 datierten Schlußwort zur Auswahl seiner deutschsprachigen politischen Aufsätze und Dokumente beurteilte Palacký die Mäßigung des ersten deutschen Reichskanzlers, Fürst Bismarck, nur als vorübergehende Taktik und entwarf als Ergebnis der jüngsten Entwicklung das düstere Bild eines für Deutschland ungünstigen Zweifrontenkrieges: „Die Deutschen überhaupt sind noch vor wenigen Jahren nicht in dem Grade hochmütig und begehrlich gewesen, wie seit den Siegen Preußens über Österreich und Frankreich: denn das waren, sagen sie, deutsche Siege, und die Deutschen haben sich nunmehr als unüberwindlich erwiesen. Ihre kriegerische Eroberungs- und Herrschsucht wächst seitdem in bedenklichem Maße, und sie glauben, nicht nur die verhaßten Slawen, sondern die ganze Welt müsse künftig ihrem Willen sich unterordnen. Sie sind nun einmal die Hegemonen in Europa. Auf wie lange? Das läßt sich nicht im voraus bestimmen. (...) Man belehrt mich in fast unglaublicher Weise, der unvermeidliche Weltkampf des Germanismus mit dem Slawismus sei bisher nur darum nicht ausgebrochen, weil der allbewunderte Staatsmann, der Mann von Blut und Eisen, der das Recht nur in der Macht erblickt, die Zeit dazu noch nicht für gekommen erachtet. Die Slawen selbst werden diesen Kampf nicht provozieren. Mag dann das Kriegsglück eine Zeit lang unentschieden hin und her wogen : am Ende, des-

\footnotetext{
12 Gustav Rasch, Aus Berlin, in: Politik (Prag), Nr. 332 vom 2. Dezember 1870, 1-3, bis Nr. 104 vom 15. April 1871, 1-2.

13 Politik, Nr. 341 vom 11. Dezember 1870, 1.

14 Ausführlich vgl. Ivan Pfaff, Tschechische Politik und die Reichsgründung, in: Jahrbücher für Geschichte Osteuropas, N.F. 20 (1972) 492-515.
} 
sen bin ich sicher, werden die Deutschen von der Überzahl ihrer Feinde im Osten und Westen dennoch erdrückt werden ..."15

Der führende alttschechische Politiker František Ladislav Rieger (1818-1903) teilte zwar die Ansicht seines Schwiegervaters František Palacký über Bismarck als einen zielbewußten und skrupellosen Staatsmann, aber in Privatgesprächen zollte er ihm oft höchste Anerkennung, besonders in sozialpolitischen Fragen ${ }^{16}$. Den tschechischen Politikern konnte es allerdings nicht entgehen, daß der wachsende machtpolitische Einfluß des Deutschen Reiches auf dem europäischen Kontinent schwerwiegende Folgen für die inneren Verhältnisse des habsburgischen Vielvölkerreiches mit sich brachte. Es konnte kein Zweifel daran bestehen, daß die offizielle reichsdeutsche Politik von 1871 an bis in den Ersten Weltkrieg hinein an der Erhaltung des Dualismus in Österreich-Ungarn und am starken Einfluß der ungarischen Regierungskreise in der Doppelmonarchie interessiert war. Die diplomatische Korrespondenz zwischen der deutschen Botschaft in Wien und dem Auswärtigen Amt in Berlin war selbstverständlich nicht öffentlich, aber zeitgenössische tschechische Kommentare fühlten ausreichend heraus, was der deutsche Geschäftsträger in Wien, Fürst Carl Maria Lichnowsky, in seinem Bericht vom 25. Oktober 1897 hervorhob: „Es ist ganz klar, daß das gesamte Deutschtum in und außerhalb Österreichs verpflichtet ist, nicht nur einem föderalistischen Staatsstreich, sondern schon der entferntesten Anbahnung einer föderalistischen Politik, oder auch nur einer Maßregel, die die Grundlage bilden könnte für die spätere Herstellung eines Wenzelreichs, entgegenzutreten. “17

Alle führenden alt- und jungtschechischen Politiker, ebenso wie die gesamte tschechische Presse äußerten gegen Ende des 19. Jahrhunderts oftmals die Überzeugung, daß der Bündnisvertrag zwischen dem Deutschen Reich und Österreich-Ungarn vom 7. Oktober 1879 den tschechischen nationalen Interessen zuwiderlaufe. Außenpolitische Vorstellungen und Wünsche der Jungtschechen befürworteten eine selbständige österreichische Außenpolitik, die weder von Deutschland abhängig, noch aber gegenüber dem Deutschen Reich feindlich wäre. Diesen Standpunkt vertrat der außenpolitische Experte der Jungtschechen, Reichsratsabgeordneter Gustav Eim (1849-1897), in einer Rede in der österreichischen Delegation in Budapest am 17. Oktober 1892: „Österreich habe in Deutschland nichts zu suchen. Nun wünschen wir nichts sehnsüchtiger, als daß auch Deutschland in Österreich nichts mehr suche. (...) Nichts steht uns ferner als irgendwelche Feindschaft gegen Deutschland. Der Haß ist ja die schlimmste Kraftvergeudung, und wir brauchen alle unsere Kräfte zu unserer nationalen Erhaltung und zur Abwehr. Wir gönnen Deutschland von Herzen seine nationale

15 Franz Palacky, Gedenkblätter. Auswahl aus Denkschriften, Aufsätzen und Briefen aus den letzten fünfzig Jahren als Beitrag zur Zeitgeschichte (Prag 1874) 312.

${ }^{16}$ Vgl. Př́spěvky k listári Dra Františka Ladislava Riegra [Beitrāge zur Briefsammlung von Dr. František Ladislav Rieger], hrsg. von Jan Heidler und Josef Susta, 2 (Historický archiv 45, Praha 1926) 160-161.

17 Politisches Archiv des Auswärtigen Amtes (im weiteren PA), Bonn, Österreich 101, Bd.6, A 12.619/1897; abgedruckt bei Jiřri Kořalka, Diplomacie Německé ř́še na konci 19. století o české svébytnosti a státnosti [Die Diplomatie des Deutschen Reiches am Ende des 19. Jahrhunderts über die tschechische Eigenständigkeit und die böhmische Staatlichkeit], in: Ceskoslovenský časopis historický 15 (1967) 121-132, hier: 126-127. 
Einigung und waren und bleiben jederzeit Gegner jedweder österreichischen Revanche-Politik, weil eine solche im Falle des Gelingens eine Wiederholung der großdeutschen, nicht nur unseren nationalen, sondern allen wirklich österreichischen Interessen zuwiderlaufenden Vormachtpolitik wäre, im Falle des Mißlingens aber wir die Kosten dieser Politik vielleicht gar mit unserer nationalen Existenz zu zahlen hätten." ${ }^{18}$

Die führenden Jungtschechen verurteilten den Dreibund zwischen dem Deutschen Reich, Österreich-Ungarn und Italien als einen antiliberalen Machtfaktor, der auf die freiheitliche Entwicklung des europäischen Kontinents hemmend wirkte. Eine Minderung der Übermacht Deutschlands hätte ihrer Meinung nach die Wiederherstellung des europäischen Gleichgewichtes mit sich gebracht. Einer der klügsten und erfolgreichsten tschechischen Politiker an der Wende des 19. zum 20. Jahrhundert, Universitätsprofessor Josef Kaizl (1854-1901), der vom März 1898 bis Anfang Oktober 1899 österreichischer Finanzminister war, hielt die öffentliche Agitation einiger Jungtschechen gegen das Bündnis mit Deutschland für einen taktischen Fehler, weil dadurch die beiden Kaiser, der österreichische wie der deutsche, gegen die Tschechen eingenommen wurden. Aber auch das aufrichtige Bemühen Kaizls, „sich mit dem Dreibund zu befreunden“, war bestenfalls der Versuch einer Aussöhnung mit dem Schicksal, einem notwendigen Übel, jedenfalls mit nichts Angenehmen ${ }^{19}$. In der tschechischen Presse wurde vornehmlich der deutsche Kaiser Wilhelm II. zum Ziel kritischer Bemerkungen, wie der erste reichsdeutsche Konsul in Prag, Freiherr Edwin von Sekkendorff, am 30. April 1899 an den Reichskanzler Fürst Hohenlohe-Schillingsfürst berichtete: „Was aber bei allen diesen Besprechungen deutscher Reichsangelegenheiten dem aufmerksamen Leser nicht entgeht, ist die Tatsache, daß neben der ostentativen Hetze gegen den Dreibund mit besonderer Freude die Namhaftmachung Seiner Majestät unseres Allergnädigsten Kaisers gepflegt wird und daß man nichts verabsäumt, den Lesern in mehr oder weniger hämischer Weise zu berichten, was den kaiserlichen Namensträger mit einer irgendwie und irgendwo nicht von allgemeinem Beifall begleiteten Aktion in Verbindung bringen kann.“20

Im Unterschied zu den Tschechen, die sich bei ihrer nationalen Emanzipation nur mit den Deutschen in den böhmischen Ländern, in der österreichischen Gesamtmonarchie und auch im außerösterreichischen Deutschland auseinandersetzten, mußten die Slowaken ihre nationale Eigenständigkeit auf drei Seiten verteidigen und durchsetzen: gegen den deutschsprachigen Einfluß in vielen Städten der heutigen Slowakei und im österreichischen Staatsapparat, gegen die immer stärkere Tendenz zur Umwandlung des supraethnischen Königreichs Ungarn in einen magyarischen Nationalstaat und gegen nationalpolitische Ansprüche der tschechischen Nationalbewegung, die in den Slowaken bloß den ungarischen Zweig der tschechisch-böhmischen Nation sehen wollte. Die schmale Schicht slowakischer Intellektueller verfolgte die deutschen

18 Gustav Eim, Die Slaven und der Dreibund. Rede des Delegierten für das Königreich Böhmen (Wien 1892) 17.

19 Josef Kaizl, Z mého života [Aus meinem Leben] 3/2, hrsg. von Zdeněk V. Tobolka (Praha 1914) 1099.

20 PA Bonn, Österreich 101, Bd. 9, A 5294/1899. 
Einheitsbestrebungen mit gewissen Sympathien, als sie in der slowakischen Presse dieselben natürlichen Rechte für die Slowaken verlangte. Das weitere Verbleiben Österreichs im Deutschen Bund schien den slowakischen Politikern und Publizisten ein großes Hindernis auf dem Weg zur Föderalisierung der Vielvölkermonarchie zu sein; in dieser Hinsicht war die slowakische Haltung mit derjenigen der tschechischen Nationalbewegung identisch ${ }^{21}$.

Das energische Auftreten Preußens in der machtpolitischen Auseinandersetzung mit Österreich im Krieg von 1866 und nachher führte bei den Slowaken zu einer Verānderung ihres herkömmlichen Bildes von Deutschland als einer Heimat der Philosophen und Dichter, höchstens noch der Handwerker und Kaufleute, das aber in der Politik nur Zerfahrenheit und wenig Kraft zeigte ${ }^{22}$. Slowakische Beobachter und Kommentatoren der politischen Entwicklung in Deutschland im Krieg von 1870/71 und in den folgenden Jahren gaben schließlich zu, daß nur Preußen die Einigung Deutschlands verwirklichen konnte, aber zugleich sahen sie in diesem militaristischen und slawenfeindlichen Junkerstaat eine große Gefahr für die Freiheit nicht nur des deutschen Volkes, sondern auch anderer europäischer Völker. Der preußische Ministerpräsident und erste deutsche Reichskanzler Fürst Bismarck erfreute sich keiner Sympathie in der slowakischen Presse, nicht zuletzt wegen seiner entschiedenen Unterstützung der magyarischen Vorherrschaft in Ungarn ${ }^{23}$.

In den letzten Jahrzehnten des 19. Jahrhunderts überwog in der slowakischen Presse ein völlig negatives Bild der Regierungspolitik des Deutschen Reiches. Das führende Presseorgan der slowakischen Nationalbewegung, Národné noviny [Nationalzeitung] in Turčiansky Svätý Martin, warf Bismarck vor, er verfolge eine polen- und tschechenfeindliche Politik und unterstütze die Suprematie der Magyaren in Ungarn ${ }^{24}$. Das deutsch-österreichisch-ungarische Bündnis von 1879 wurde in dieser Zeitung als eine gegen das Slawentum in und außerhalb Österreichs gerichtete Maßnahme bezeichnet. Der einflußreiche slowakische Schriftsteller und Journalist Svetozár Hurban Vajanský (1847-1916) verurteilte in mehreren Leitartikeln die reichsdeutsche Politik als eine aggressive Bedrohung des Friedens in Europa. Er und seine Mitarbeiter in der konservativen Slowakischen Nationalpartei neigten schließlich dazu, die einzige Hoffnung auf die Befreiung der Slawen in Ungarn und auf dem Balkan in der angekündigten Konflagration des Germanismus mit dem Slawismus und im erwarteten Sieg Rußlands zu sehen; damit begründeten sie auch ihre innenpolitische Passivität. In der Artikelserie „Germanien im Zenit der Stärke“ stellte Vajanský den positiven Einfluß Deutschlands in der „Lehrerepoche“ an der Wende des 18. zum 19. Jahrhundert der Politik des Egoismus und der brutalen Macht nach der Reichsgründung entgegen:

${ }^{21}$ Mikuläš Písch, Slovenské pohl'ady na štátnozjednocovací proces Nemecka [Der staatliche Einigungsprozeß Deutschlands in slowakischer Sicht], in: Historický časopis 19 (1971) 335-355.

${ }_{22}$ In diesem Sinne außerte sich die leitende Persönlichkeit der slowakischen Nationalbewegung, L'udovít Stúr, Das Slawenthum und die Welt der Zukunft, hrsg. von Josef Jirásek (Bratislava 1931, Originalmanuskript um 1854) 110-111.

${ }^{23}$ Písch, Slovenské pohl'ady, 349.

${ }^{24}$ Mikulás Písch, Trojspolok a Dohoda v slovenskej buržoáznej politike (1879 až 1907) [Der Dreibund und die Entente in der slowakischen bürgerlichen Politik 1879 bis 1907], in: Historický časopis 23 (1975) 533-542. 
„Alle Völker fühlen das Joch der deutschen Übermacht und finden sich auf einmal, durch das Gefühl der Selbstrettung getrieben, in einem Lager gegen die deutsche geistlose Maschine verbunden. “25

In der tschechischen Öffentlichkeit erregte die gegen die Polen gerichtete preußisch-deutsche Politik großes Mißfallen. Ebensowenig konnte der befürchtete Expansionsdrang Deutschlands über die böhmischen Länder hinaus nach dem Südosten bei den Tschechen Unterstützung finden ${ }^{26}$. Dennoch zeigte das Deutsche Reich zwischen 1871 und 1914 vielen tschechischen Studenten, Künstlern, Wissenschaftlern und Technikern ein freundlicheres Gesicht, als dies in den Einschätzungen der reichsdeutschen Innen- und Außenpolitik in tschechischen Zeitungen der Fall war. Mehr Gehör fand die in erster Linie durch Universitätsprofessor Tomáš Garrigue Masaryk (18501937), seine Studenten und Anhänger repräsentierte Gruppe europäisch denkender Tschechen bei reichsdeutschen Linksliberalen, Sozialdemokraten, Freidenkern und kosmopolitisch orientierten Juden. Deutschsprachige Fassungen der polemischen Schriften Masaryks gegen Verleumdungen von Art jüdischer Ritualmorde erschienen in Berlin, diejenigen gegen den österreichischen Klerikalismus in Frankfurt am Main $^{27}$. Das zweibändige bahnbrechende Werk Masaryks über die russische geistige Tradition wurde bei Eugen Diederichs in Jena herausgegeben ${ }^{28}$. Moderne tschechische Maler und Bildhauer, schätzten die guten Ausstellungsmöglichkeiten in Düsseldorf, Köln, Berlin und anderswo in Deutschland ${ }^{29}$.

Auch im slowakischen politischen und kulturellen Leben war seit dem Ende des 19. Jahrhunderts eine Differenzierung zu beobachten. Die unkritische Russophilie der alten Führung in Turčiansky Svätý Martin konnte die junge Generation slowakischer Intellektueller, die zum Teil unter dem Einfluß Masaryks an der tschechischen Universität in Prag herangewachsen waren, nicht mehr zufriedenstellen ${ }^{30}$. Eine weltoffene Haltung, auch gegenüber Deutschland, nahmen vor allem lutheranische Slowaken ein, von denen einige an reichsdeutschen Universitäten studiert hatten. Der später als Führer der slowakischen Agrarier bekannte Journalist Milan Hodža (1878-1944) vertrat von 1901 an zielbewußt den Grundsatz der Demokratie in der Politik, den er auch

25 Pisch, Trojspolok a Dohoda, 536.

${ }^{26}$ Ausführlich dazu Josef Fortt, Ven z přttmí! Českých snah pohnutky, cíle a cesty [Hinaus aus dem Halbdunkel! Die Beweggründe, Ziele und Wege der tschechischen Bestrebungen] (Praha 1905) 174-186. Vgl. Koralka, Tschechen im Habsburgerreich, 272-273.

${ }_{27}$ T. G. Masaryk, Die Bedeutung des Polnaer Prozesses für den Ritualglauben (Berlin 1900); ders., Ein Katechetenspiegel, 1: Die Masarykprozesse; 2. Wissenschaft und Religion, Religion und Schule; 3. Der Katechetenspiegel (Frankfurt am Main 1906). Vgl. Roland J. Hoffmann, T. G. Masaryk und die tschechische Frage 1: Nationale Ideologie und politische Tätigkeit bis zum Scheitern des deutsch-tschechischen Ausgleichsversuchs vom Februar 1909 (Veröffentlichungen des Collegium Carolinum 58, München 1988) 199-203, 271-272, 466-467.

${ }_{28} T$. G. Masaryk, Rußland und Europa. Studien über die geistigen Strömungen in Rußland. Zur russischen Geschichts- und Religionsphilosophie. Soziologische Skizzen 1-2 (Jena 1913).

${ }^{29}$ Vgl. Miroslav Lamač, Die Entwicklung und Resonanz des tschechischen Kubismus, in: Kubismus in Prag 1909-1925. Malerei, Skulptur, Kunstgewerbe, Architektur, hrsg. von Jiř́ Švestka und Tomás Vlček (Stuttgart 1991) 59-60.

30 Michal Potemra, Die slowakische Frage im europäischen Kontext in den Jahren 1901-1914, in: Studia Historica Slovaca 12 (1982) 119-157. 
auf das Verhältnis zu anderen Völkern ausdehnen wollte ${ }^{31}$. Hodža gehörte vor 1914 zu den Vertrauensleuten des österreichischen Thronfolgers, Erzherzog Franz Ferdinand, und mit ihm teilte er einen reservierten Standpunkt zum wilhelminischen Deutschland $^{32}$.

Der Ausbruch des Ersten Weltkriegs im Juli/August 1914 konfrontierte die tschechische Politik und die gesamte tschechische Gesellschaft mit einem verstärkten Druck der reichsdeutschen Regierungskreise auf die inneren Verhältnisse des Habsburgerreiches. Keine politische Gruppe unter den Tschechen konnte sich mit einem Krieg gegen die damals einzigen slawischen Staaten, Rußland, Serbien und Montenegro, identifizieren. In großen Teilen der Bevölkerung trat die tschechische Unzufriedenheit mit dem Krieg viel stärker zutage als in den meisten Parteiführungen, wobei das Deutsche Reich in erster Linie für den Krieg verantwortlich gemacht wurde. Der deutsche Konsul Freiherr Friedrich von Gebsattel berichtete aus Prag am 20. Dezember 1914, nachdem er die - wie er es bezeichnete - hämischen und mißgünstigen Besprechungen der Ereignisse auf den Kriegsschauplätzen in der führenden tschechischen Tageszeitung Národní listy [Nationalblätter] und das Verbot der Zeitungen Samostatnost [Selbstständigkeit] und České slovo [Tschechisches Wort] erwähnt hatte: „In dem Gebahren der Presse kommt so recht die Stimmung und Haltung der Tschechen zum Ausdruck. Zu Beginn des Krieges herrschte ja unter den Tschechen eine den Eindruck der Aufrichtigkeit machende Begeisterung für die Bündnistreue des Deutschen Reiches. (...) Dieser Enthusiasmus für Deutschland ist längst abgekühlt und so gut wie in das Gegenteil umgeschlagen. In den tschechischen Kaffeehäusern und Restaurants können nicht genug Exemplare derjenigen italienischen und sonstigen ausländischen Zeitungen gehalten werden, die in einem für Deutschland und Österreich gehässigen Sinne über den Krieg berichten. Nachrichten über angebliche Mißerfolge Deutschlands und - was besonders hervorgehoben zu werden verdient Österreichs erregen die Freude der Tschechen und werden gerne geglaubt. (...) Als charakteristisch möchte ich noch erwähnen, daß in einer Vorstellung in einem hiesigen Kinematographen, der ein Angestellter des Konsulats anwohnte, vom tschechischen Publikum gezischt wurde, als das Bild des Feldmarschalls von Hindenburg erschien. Es unterliegt gar keinem Zweifel, daß das tschechische Volk illoyal und sogar hochverräterisch denkt und fühit." ${ }^{\text {(33 }}$

In Prag war man sich der Tatsache bewußt, daß der seit dem Ausbruch des Ersten Weltkriegs massiv verbreitete deutsche Mitteleuropagedanke seinem Wesen nach gegen die Selbständigkeit des österreichischen Staates und gegen den vor 1914 erreichten Status der tschechischen Gesellschaft in diesem Staat gerichtet war. Die tschechische Reaktion auf verschiedene deutsche Mitteleuropapläne, besonders auf das Buch

"Dušan Kováč, Liberalismus, Demokratie und die slowakische Nationalbewegung am Anfang des 20. Jahrhunderts, in: Ungleiche Nachbam. Demokratische und nationale Emanzipation bei Deutschen, Tschechen und Slowaken (1815-1914), hrsg. von Hans Mommsen und Jiř́ Koralka (Veröffentlichungen des Instituts für Kultur und Geschichte der Deutschen im östlichen Europa 1, Essen 1993) 81-90, hier 86-87.

32 Vgl. Robert A. Kann, Erzherzog Franz Ferdinand Studien (Veröffentlichungen des Österreichischen Ost- und Südosteuropa-Instituts 10, Wien 1976) 43-45.

33 PA Bonn, Österreich 101, Bd. 35, A 35.838/1914. 
von Friedrich Naumann ${ }^{34}$, war dabei nicht eindeutig negativ. In den Jahren 1915 bis 1916 versuchten tschechische Politiker und Publizisten, sorgfältig zwischen einzelnen Schattierungen der Mitteleuropaidee zu unterscheiden, wobei jede kleine Spur einer Verständigungsmöglichkeit mit Deutschland unter Wahrung der tschechischen Eigenständigkeit begrüßt wurde. Der tschechische sozialdemokratische Reichsratsabgeordnete Bohumír Šmeral (1880-1940), von August 1916 an Vorsitzender des Exekutivkomitees seiner Partei ${ }^{35}$, unternahm im Jahre 1915 wiederholt Versuche, linksliberale und sozialdemokratische Kreise im Deutschen Reich gegen den engstirnigen tschechenfeindlichen Nationalismus zu gewinnen. Ende Juli 1915 veröffentlichte Friedrich Naumann, ohne den Verfasser zu nennen ${ }^{36}$, einen ausführlichen Hilferuf Šmerals zum Anknüpfen freundschaftlicher Beziehungen zwischen den Reichsdeutschen und den Tschechen: „Der noch engere Anschluß an die Westkultur, namentlich an die deutsche, wird ausschlaggebend werden müssen. Hier müssen die Deutschen in Deutschland dem kleinen tschechischen Volke entgegenkommen, weil sonst das Gefühl der überaus empfindsamen und empfindlichen Tschechen, als sollten sie sich an die Deutschen demütig anbiedern, alles verderben möchte. Die Deutschen im Reiche müssen ein Interesse an den kulturellen und wirtschaftlichen Bestrebungen der Tschechen zeigen. ${ }^{\text {"37 }}$

Selbst die kleinsten Anzeichen einer positiven Anerkennung tschechischer Leistungen in der reichsdeutschen Presse wurden tschechischerseits registriert, wenn sie auch nicht häufig waren. In der Atmosphäre der deutschen Kriegserfolge wollten jedoch nicht nur alldeutsche Annexionisten, sondern auch gemäßigtere Regierungspolitiker in Berlin an der Maxime einer uneingeschränkten deutschen Herrschaft in den böhmischen Ländern festhalten ${ }^{38}$. So konnte die deutsche Mitteleuropapropaganda als Ausdruck eines unersättlichen deutschen Imperialismus der tschechoslowakischen Auslandsaktion von T. G. Masaryk und Edvard Beneš (1884-1948) in den Ententeländern gute Dienste erweisen. Das Memorandum Masaryks vom Februar 1916 hatte den bezeichnenden Titel „L'Europe centrale pangermanique, ou Bohême libre?“. Im Gegensatz zu den deutschen Plänen erklärte Masaryk die staatliche Unabhängigkeit Polens, Böhmens und der südslawischen Länder für die notwendige Voraussetzung eines

34 Friedrich Naumann, Mitteleuropa (Berlin 1915); Nachdruck in: ders., Werke 4: Schriften zum Parteiwesen und zum Mitteleuropaproblem, hrsg. von Theodor Scbieder, bearbeitet von Thomas Nipperdey und Walfgang Scbieder (Köln, Opladen 1964) 485-766.

35 Vgl. Jan Galandauer, Bohumír Šmeral 2: 1914-1941 (Praha 1986) 63.

36 Die Autorenschaft Šmerals bestätigt Peter Theiner, Sozialer Liberalismus und deutsche Weltpolitik. Friedrich Naumann im Wilhelminischen Deutschland 1860-1919 (Schriften der Friedrich-Naumann-Stiftung, Baden-Baden 1983) 241.

37 (Bobumir Smeral), Prager Brief von einem tschechischen Abgeordneten des österreichischen Reichstages, in: Die Hilfe, Jg. 21, Nr. 30 vom 29. Juli 1915, 481.

${ }^{38} \mathrm{Vgl}$. L'Allemagne et les problèmes de la paix pendant la première guerre mondiale. Documents extraits des archives de l'Office allemand des Affaires étrangères 1 : Des origines à la déclaration de la guerre sous-marine à outrance (août 1914-31 janvier 1917), hrsg. von André Scherer und Jacques Grunewald (Publications de la Faculté des Lettres et Sciences humaines de Paris, Textes et documents 3, Paris 1962) 227 u.a. 
freien Mitteleuropas ${ }^{39}$. Gegen Ende 1917 setzte Masaryk das Programm eines „neuen Europa" souverāner Nationen ausdrücklich gegen ein deutsches Mitteleuropa ab" ${ }^{40}$. Es kann nicht übersehen werden, daß Masaryk und Beneš in ihren Betrachtungen das machtpolitische und wirtschaftliche Interesse Frankreichs und Großbritanniens an Mitteleuropa überschätzten und die Regenerationskraft Deutschlands nach dem Kriege nicht genug in Erwägung zogen.

Je mehr sich der für Deutschland und Österreich-Ungarn ungünstige Ausgang des Ersten Weltkriegs näherte, desto wichtiger schien das Anknüpfen direkter Kontakte zwischen den Reichsdeutschen und den Tschechen zu sein, wenn auch zunāchst auf inoffizieller Ebene. Führende tschechische Politiker in Prag machten kein Hehl aus ihrer Überzeugung, daß die österreichische Politik in der letzten Kriegsphase immer stārker von Berlin aus bestimmt wurde. Als der liberale Redakteur der Vossischen Zeitung, Alexander Redlich, in der zweiten Maihälfte 1918 nach Prag kam, um die damalige Situation in Böhmen persönlich kennenzulernen, mußte er zur Kenntnis nehmen, daß auch die tschechischen Politiker in Prag, nicht nur Masaryk und Beneš im Ausland, über die künftige Stellung des tschechischen bzw. tschechoslowakischen Staates in Europa Überlegungen anstellten: „Ich habe in Prag in einer einzigen Woche mehr über auswärtige Politik, über Weltfragen reden gehört und reden müssen als in Wien während des ganzen vorhergegangenen Monats. Ich habe begriffen, daß auf dem bisherigen Weg eine deutsch-tschechische Einigung innerhalb Böhmens deshalb nicht möglich ist, weil der Horizont der deutschen Ausgleichsvorschläge und Polemiken kaum über die Begriffe Pilsen, Budweis und Trautenau hinausgeht, während die Tschechen sich bereits über die künftige Gestaltung des europäischen Erdteils ihre Gedanken machen. (...) Die Tschechenfrage reduziert sich demnach schließlich, wenn man den tschechischen Gedankengängen folgen will, auf die einfachste Formel: ,Kann sich Prag mit Berlin politisch verständigen oder nicht? ‘ “41

Tatsächlich waren viele tschechische Politiker, Handels- und Finanzleute an einer direkten Verständigung mit dem Deutschen Reich aufrichtig interessiert ${ }^{4 \mathbf{2}}$. In der hastigen Umsturzatmosphäre, unmittelbar nach der Ausrufung des tschechoslowakischen Staates durch den von Vertretern aller tschechischen Parlamentsparteien gebildeten Nationalausschuß am 28. Oktober 1918, nahmen daher die provisorischen Träger der Staatsmacht in Prag mit Genugtuung zur Kenntnis, daß der offizielle Vertreter des Deutschen Reiches in Prag, Generalkonsul (von Februar 1915 an mit diesem Titel) Freiherr von Gebsattel, auf eigene Initiative die Anerkennung des tschechoslowaki-

39 Zusammengefaßt bei Karel Pichlik, Zahraniční odboj 1914-1918 bez legend [Der Auslandswiderstand 1914-1918 ohne Legenden] (Praha 1968) 174-175.

${ }^{40}$ In deutscher Ubersetzung vgl. T. G. Masaryk, Das neue Europa. Der slavische Standpunkt (Berlin 1922).

4 Union (Prag), Jg. 10, Nr. 153 vom 6. Juni 1918, 1 (Nachdruck aus der Vossischen Zeitung).

42 Ein hervorragender tschechischer Finanzmann, wahrscheinlich Jaroslav Preiss, Direktor der Prager Živnostenská banka, forderte in einem Interview im Neuen Wiener Tagblatt (auch in der Vossischen Zeitung abgedruckt) eine dauerhafte Verständigung des tschechischen Staates mit Deutschland. Koloman Gajan, Německý imperialismus a československo-německé vztahy v letech 1918-1921 [Der deutsche Imperialismus und die tschechoslowakisch-deutschen Beziehungen in den Jahren 1918-1921] (Praha 1962) 24. 
schen Staates durch Deutschland aussprach ${ }^{43}$. Das geschah am 2. November 1918, vor dem Waffenstillstand der Entente mit Österreich-Ungarn und neun Tage vor dem Verzicht Kaiser Karls auf Teilnahme an den Staatsgeschäften. Die deutsche Reichsregierung interpretierte diesen Schritt als eine De-facto-Anerkennung ${ }^{44}$, aber juristisch blieb die Erklärung Gebsattels im Bereich des Unverbindlichen, von beiden Seiten bestreitbar ${ }^{45}$.

In den Regierungskreisen der Tschechoslowakischen Republik traten von Anfang an zwei abweichende Tendenzen in der Einschätzung des Deutschen Reiches nach dem Kriegsende zutage. Ein starkes Mißtrauen gegen das Überleben militärischer und expansionistischer Gesinnungen in Deutschland herrschte in tschechischen rechtsnationalen Parteien vor. So erklärte der aus der Vorkriegszeit bekannte jungtschechische, nunmehr nationaldemokratische Führungspolitiker und erster tschechoslowakischer Ministerpräsident, Karel Kramář (1860-1937), in der Prager Nationalversammlung am 12. Dezember 1918, daß die Tschechoslowakei „mit Polen und dem südslawischen Staate einen Damm gegen die Expansivkraft des Deutschen Reiches, einen Wall gegen den germanischen Militarismus bilden“ müsse ${ }^{46}$. Nur zehn Tage später, am 22. Dezember 1918, behandelte die erste Botschaft des eben aus dem Ausland zurückgekehrten Präsidenten der Tschechoslowakischen Republik, Tomáš Garrigue Masaryk, an die Nationalversammlung dasselbe Problem in einem versöhnlicheren Tone: „Unser Verhältnis zu Deutschland werden wir danach einrichten, welche Politik es einschlägt. Wir werden uns korrekt verhalten; wir wünschen, daß die Niederlage des preußischen aggressiven Militarismus zum Sieg des deutschen Volkes werde, daß das deutsche Volk sich auf seine nationalen Kräfte einzuschränken gewöhne, daß es seine expansive Politik nach Osten aufgebe und seine großen Kräfte und Fähigkeiten der internationalen Organisation der Völker und der Menschheit widme. Das ist ein viel größeres und erhabeneres Ziel als das pangermanische Ziel.“47

Die Ausdrucksweise der ersten Botschaft T. G. Masaryks erinnerte zum Teil noch an seine Kriegsschriften, und gegenüber den Deutschböhmen war sie wenig entgegenkommend $^{48}$, aber im Grunde war schon hier das tschechische Interesse an einer

${ }^{43}$ Deutsche Gesandtschaftsberichte aus Prag. Innenpolitik und Minderheitenprobleme in der Ersten Tschechoslowakischen Republik, 1: Von der Staatsgründung bis zum ersten Kabinett Beneš 1918-1921. Berichte des Generalkonsuls von Gebsattel, des Konsuls König und des Gesandten Professor Saenger, hrsg. von Manfred Alexander (Veröffentlichungen des Collegium Carolinum 49/I, München-Wien 1983) 50-53.

44 Die Regierung des Prinzen Max von Baden, hrsg. von Erich Mattbias und Rudolf Morsey (Quellen zur Geschichte des Parlamentarismus und der politischen Parteien I/2, Düsseldorf 1962) 482, 510-511.

45 In diesem Sinne Manfred Alexander, Die erste Phase der deutsch-tschechoslowakischen Beziehungen, in: Die böhmischen Länder zwischen Ost und West. Festschrift für Karl Bosl zum 75. Geburtstag, hrsg. von Ferdinand Seibt (Veröffentlichungen des Collegium Carolinum 55, München, Wien 1983) 228-239, hier: 234.

${ }^{46}$ Deutsche Gesandtschaftsberichte 1, 113.

${ }^{47}$ Národní shromáždění československé v pruním roce republiky [Die tschechoslowakische Nationalversammlung im ersten Jahr der Republik] (Praha 1919) 79-80; zit. nach Gajan, Německý imperialismus, 52 .

48 Deutsche Gesandtschaftsberichte 1, 127-128. 
Differenzierung des politischen Lebens in Deutschland und an möglichst guten Beziehungen zu den reichsdeutschen liberalen und demokratischen Kräften angedeutet. Diese Haltung war in der ganzen Zwischenkriegszeit charakteristisch für die einflußreiche Gruppe um die Prager Burg ${ }^{49}$, von tschechischen politischen Parteien in erster Linie für die Sozialdemokratie. Im Gespräch mit dem inoffiziellen Abgesandten des Berliner Auswärtigen Amtes, Geheimrat Julius Wolf, einem alten Bekannten des tschechoslowakischen Präsidenten, erklärte T. G. Masaryk im Februar 1919, daß die tschechische Stimmung Deutschland gegenüber eine andere als gegenüber Deutschösterreich sei. In Prag wünsche man gute Beziehungen zu Deutschland und ein Einvernehmen in absehbarer Zeit, vor allem aus wirtschaftlichen Gründen und angesichts der geographischen Lage der Tschechoslowakei ${ }^{50}$. Samuel Saenger, von Juni 1919 an der bevollmächtigte Vertreter des Deutschen Reiches in Prag, berichtete über die aufrichtige Hoffnung nicht nur des Staatspräsidenten Masaryk ${ }^{51}$, sondern auch des sozialdemokratischen Ministerpräsidenten Vlastimil Tusar (1880-1924), daß sich demokratische Kräfte in Deutschland durchsetzen werden. In diesem Sinne schrieb Saenger aus Prag am 11. August 1919: „... Der Glaube an die Zukunft der reichsdeutschen Demokratie nimmt in auffallendem Maße zu. Man traut Deutschland die Kraft zu, in absehbarer Zeit und zuerst in Europa, eine vorbildliche soziale Demokratie zu errichten. Diesem Glauben gab mir gegenüber Ministerpräsident Tusar unverhohlen Ausdruck, und er meint, je mehr sich dieser Glaube als berechtigt erweise, desto schneller und gründlicher würde der Haß gegen Deutschland abklingen und der Anerkennung und Bewunderung Platz machen. ${ }^{\text {"52 }}$

Die unangefochtene Schlüsselposition in der auswärtigen Politik der Tschechoslowakei, auch in den Beziehungen zum Deutschen Reich, nahm Edvard Beneš ein, der langjährige Außenminister und engste Mitarbeiter Masaryks seit den Kriegsjahren. Von Anfang an war sich Beneš der schicksalhaften Lage der Tschechoslowakischen Republik am Schnittpunkt der europäischen Großmachtpolitik bewußt. In seinem ersten großen Exposé vor der Prager Nationalversammlung am 30. September 1919 erklārte Beneš dazu: „Auf unserem Territorium werden nämlich immer drei große Strömungen zusammenlaufen: der westliche Einfluß, der germanische Einfluß und der russische (slawische) Einfluß. Es handelt sich darum, daß wir aus diesen drei großen Faktoren eine Mittelposition zu schaffen wissen, in der wir niemals ein Werkzeug irgendeines von diesen Faktoren werden, in der wir unsere gewichtige und bedeutende Stellung behaupten, unsere eigene politische Intellektualität und hohe Kultur ausbilden und wirklich eigenständig werden. ${ }^{\text {“53 }}$

49 Dazu vgl. Die „Burg“. Einflußreiche politische Kräfte um Masaryk und Beneš, hrsg. von Karl Bosl, 2 Bde. (Vorträge der Tagungen des Collegium Carolinum. München, Wien 1973-1974).

so Deutsche Gesandtschaftsberichte 1, 149-150.

31 Ebd. 157-158.

52 Ebd. 186.

${ }^{53}$ Edvard Beneš, Problémy nové Evropy a zahraniční politika československá. Projevy a úvahy z roku 1919-1924 [Probleme des neuen Europa und die tschechoslowakische Außenpolitik. Reden und Überlegungen aus den Jahren 1919-1924] (Praha 1924); zit. nach Vèra Olivová, Ceskoslovensko v rozrušené Evropě [Die Tschechoslowakei im zerrütteten Europa] (Praha 1968) 109. 
Nach der Ansicht von Beneš konnte der tschechoslowakische Staat kein Interesse daran haben, seine Nachbarn unnötig zu reizen. Aus diesem Grunde wollte er das Verhältnis zum Deutschen Reich möglichst korrekt und loyal gestalten, und zwar nicht nur weil sich Deutschland von allen Nachbarstaaten gegenüber der Tschechoslowakei am korrektesten benommen hatte, sondern auch aus eigenem wirtschaftlichen Interesse. Die tschechoslowakische Außenpolitik weigerte sich, die auf eine zu starke wirtschaftliche Belastung Deutschlands hinwirkenden Forderungen der französischen Regierung in vollem Ausmaß zu unterstützen, weil die Tschechoslowakei von einer Schwächung der deutschen Währung und von Handelsschwierigkeiten mitbetroffen gewesen wäre $^{54}$. Mit großem persönlichen Einsatz wirkte Edvard Beneš vor allem im Genfer Völkerbund, wo er sich unter anderem für die Aufnahme des Deutschen Reiches einsetzte. Damit Deutschland den Beitritt reibungslos vollziehen konnte, erklärte sich die Tschechoslowakei bereit, ihren Sitz im Völkerbundrat zur Verfügung zu stel$\operatorname{len}^{35}$. Es scheint, daß Beneš Interesse daran hatte, die Beziehungen zum Deutschen Reich in den 1920er Jahren in einem rosigeren Licht darzustellen, als sie in Wirklichkeit waren. Doch konstatierte auch eine im Berliner Auswärtigen Amt Anfang März 1927 vorbereitete Aufzeichnung für den deutschen Außenminister: „Die politische Atmosphäre in den Beziehungen zwischen dem Reich und der Tschechoslowakei hat im letzten Jahr eine bemerkenswerte Besserung erfahren, worauf in jüngster Zeit gerade von tschechoslowakischer Seite (Präsident Masaryk in verschiedenen Zeitungsinterviews, Außenminister Beneš in seinen Ausführungen vor den außenpolitischen Ausschüssen des Senats und des Abgeordnetenhauses und sogar der Führer der tschechischen Nationaldemokraten Kramár) mit besonderer Betonung hingewiesen worden ist." 56

Es ist bezeichnend, daß rechtsnationale Parteien und Gruppen bei den Tschechen und auch bei den Slowaken - es waren exakt diejenigen Parteien und Politiker, die dann nach dem September 1938 aufs engste mit dem Hitler-Deutschland zusammenarbeiten sollten - in den 1920er Jahren sehr stark und laut deutschfeindlich auftraten. Organisierte Ausflüge tschechischer Legionäre in vorwiegend deutschsprachige Städte Nord- und Westböhmens wurden in diplomatischen Berichten als solche „ein[es] Prätorianerregiment $[\mathrm{s}]$ neben der Regierung" bezeichnet und mit dem Faschistenunfug in Italien verglichen ${ }^{57}$. Die 1925 nach italienischem Vorbild gegründete Nationale Faschistengemeinde blieb am Rande des tschechischen politischen Lebens, aber ihre am Beispiel der Weimarer Republik dokumentierte Abneigung gegen den jüdischen Li-

s4 Věra Olivová, Československá diplomacie v době rurské krize roku 1923 [Die tschechoslowakische Diplomatie in der Zeit der Ruhrkrise im Jahre 1923], in: Československý časopis historický 6 (1958) 59-70; Manfred Alexander, Die Tschechoslowakei und die Probleme der Ruhrbesetzung 1923, in: Bohemia 12 (1971) 297-336.

ss Peter Burian, Die Tschechoslowakei als Mitglied des Völkerbunds, in: Gleichgewicht - Revision - Restauration. Die Außenpolitik der Ersten Tschechoslowakischen Republik im Europasystem der Pariser Vororteverträge, hrsg. von Karl Bosl (Vorträge der Tagungen des Collegium Carolinum, München, Wien 1976) 183-200, hier: 196.

56 Akten zur deutschen auswärtigen Politik (im weiteren ADAP), Serie B: 1925-1933, 4: 1. Januar bis 16. März 1927 (Göttingen 1970) 456-457.

${ }^{57}$ Deutsche Gesandtschaftsberichte 1, 519. 
beralismus und den angeblich verkommenen Parlamentarismus war am rechten Flügel des tschechischen parteipolitischen Spektrums nicht vereinzelt ${ }^{58}$. Auch in der $\mathrm{Na}$ tionaldemokratischen Partei erhoben einflußreiche Kritiker im März/April 1927 Einspruch gegen die Teilnahme sudetendeutscher Minister an der Regierung und gegen die Annäherung der Tschechoslowakei an Deutschland ${ }^{59}$. In der für die Autonomie der Slowakei kämpfenden Slowakischen Volkspartei wurden ,antideutsche Äußerungen“ des Parteiführers Andrej Hlinka (1864-1938) von einigen jüngeren Funktionären als „nur eine Marotte des alten Herrn“ herabgespielt ${ }^{60}$, aber der konservativ-katholische Slawismus der Volkspartei war seinem Wesen nach deutschfeindlich.

Ähnliche gegensätzliche Tendenzen zeigten sich im tschechischen Verhältnis zum Deutschen Reich auch im Bereich von Bildung und Kunst. Im Jahre 1924 gab Otakar Vočadlo (1895-1974), damals Dozent für englische Sprache und Literatur an der tschechischen Universität in Prag, eine feurige polemische Schrift „V zajetí babylonském“ "In der babylonischen Gefangenschaft] heraus. Er zählte hier die angeblich verderblichen deutschen Einflüsse auf die tschechische Sprache und Literatur, auf die Lebensweise und die Gedankenwelt der Tschechen auf und empfahl dagegen eine angloamerikanische Orientierung ${ }^{61}$. Demgegenüber zeigte jede verläßliche Analyse tschechischer Übersetzungen aus fremdsprachiger Literatur, daß aus der älteren, neueren und neuesten deutschen Literatur weitaus mehr als aus anderen Sprachen übersetzt wurde; als Beispiel wurde angeführt, daß Gerhart Hauptmann und Bernhard Kellermann bis zum Jahre 1938 je zehn tschechische Ausgaben, Hans Fallada sechs Ausgaben, Hermann Hesse drei Übersetzungen ins Tschechische autweisen konnten, daß die tschechische Ausgabe der Werke Goethes eine der vollständigsten überhaupt war und daß moderne deutsche Romane guter Qualitāt spätestens binnen zwei Jahren in tschechischer Sprache erschienen ${ }^{62}$. Die Berliner Theaterwelt wurde auch in Prag hochgeschätzt, Ausstellungen moderner deutscher Kunst verzeichneten im Prager Kunstverein „Mánes“ großen Erfolg ${ }^{63}$. Tschechischerseits wurden allerdings solche Strömungen und Persönlichkeiten der deutschen Literatur und Kunst bevorzugt, die nicht national, sondern europäisch und humanistisch orientiert waren.

Bis etwa zum Tode Gustav Stresemanns im Oktober 1929 waren die Beziehungen

\footnotetext{
58 Vgl. Josef Harna, Reakce českých fašistů na nástup Hitlera k moci v Německu [Die Reaktion tschechischer Faschisten auf die Machtergreifung Hitlers in Deutschland], in: Sborník k problematice dějin imperialismu 13 (Praha 1982) 85-88.

59 Vgl. Jaroslav César und Bobumil Černý, Politika německých buržoazních stran v Československu v letech 1918-1938 [Politik der deutschen bürgerlichen Parteien in der Tschechoslowakei in den Jahren 1918-1938] 1: 1918-1929 (Praha 1962) 377.

60 ADAP, B-5: 17. März bis 30. Juni 1927 (Göttingen 1972) 349.

${ }^{61}$ Otakar Vočadlo, V zajetí babylonském. Německé vlivy na nás [In der babylonischen Gefangenschaft. Deutsche Einflüsse auf uns] (Knihy Nových Čech 3, Praha 1924).

${ }_{62}$ František Novotný, Co jsme znali z nèmecké literatury [Was kannten wir aus der deutschen Literatur], in: Literární noviny (Praha), Jg. 12, Nr. 6 vom Juni 1939, 123-124.

${ }^{63} \mathrm{Vgl}$. Harald Olbrich, Zu Beziehungen und zur Zusammenarbeit zwischen progressiven deutschen und tschechoslowakischen Künstlem 1918 bis 1939, in: Deutsch-tschechische Beziehungen im Bereich der Sprache und Kultur, hrsg. von Bobuslav Havránek und Rudolf Fischer (Berlin 1965) 169-180; hier: 173.
} 
zwischen der Tschechoslowakischen Republik und dem Deutschen Reich mehr als korrekt, zuletzt fast freundschaftlich ${ }^{64}$. Einerseits legte die deutsche Außenpolitik der Tschechoslowakei (ohne Rücksicht auf die Beschwerden eines Teiles der Sudetendeutschen) keinesfalls eine solche Bedeutung wie dem polnischen Problem bei, andererseits hatte die Tschechoslowakei größere Probleme mit anderen Nachbarn, besonders mit Ungarn und Polen, als mit dem Deutschen Reich. Den Wunsch, die Beziehungen zu Deutschland enger zu gestalten, äußerte auf tschechischer Seite in erster Linie die Agrarpartei des Ministerpräsidenten Antonín Švehla (1873-1933) aufgrund gemeinsamer Wirtschaftsinteressen ${ }^{65}$. Die tiefe Weltwirtschaftskrise und die innenpolitische Wende in Deutschland nach dem Sturz des sozialdemokratischen Reichskanzlers Hermann Müller im März 1930 unterbrachen endgültig die Tendenz zur deutsch-tschechoslowakischen Annäherung. Es gelang zwar, den großangelegten Plan einer deutsch-österreichischen Zollunion vom März $1931 \mathrm{zu}$ vereiteln ${ }^{66}$, aber die Großwetterlage zwischen Deutschland und der Tschechoslowakei verschlechterte sich zusehends. Mehrtägige Straßendemonstrationen gegen deutsche Tonfilme in Prag im September 1930 wurden zwar zum Teil provoziert ${ }^{67}$, die tschechische Öffentlichkeit beobachtete jedoch die politische Entwicklung im benachbarten Deutschland mit zunehmender Besorgnis.

Gegenüber dem nationalsozialistischen Deutschland nach dem 30. Januar 1933 nahm die offizielle tschechoslowakische Außenpolitik begreiflicherweise eine viel rücksichtsvollere Haltung ein als die tschechische demokratische Öffentlichkeit, in der Adolf Hitler und die deutschen Nationalsozialisten zu beliebten Objekten von Karikaturen, politischen Theaterstücken und Spottliedern wurden ${ }^{68}$. Gleich in den Tagen der Machtergreifung äußerte der tschechoslowakische Außenminister Edvard Beneš einen Gedanken, der sich auf längere Sicht als richtig erweisen sollte: „Wir werden mit Deutschland keinen Krieg führen; wir haben eine allgemeine europäische Katastrophe zu fürchten, nie aber einen Krieg mit Deutschland.“69

Die verantwortlichen Leiter der tschechoslowakischen Außenpolitik hatten Sorgen um die innere Entwicklung des Deutschen Reiches, aber sie überschätzten zunächst die Kontinuität der außenpolitischen Ziele der Weimarer Republik unter der Herrschaft der deutschen Nationalsozialisten und sahen nach wie vor Italien, Ungarn und eine mögliche Rückkehr der Habsburger nach Wien als die Hauptgefahr für die

64 F. Gregory Campbell, Confrontation in Central Europe: Weimar Germany and Czechoslovakia (Chicago, London 1975) 110. Der Verfasser unterscheidet „correct relations“ 1921-1925, „friendly relations“ 1925-1929 und „radicalization“ 1929-1933.

65 Peter Krüger, Beneš und die europäische Wirtschaftskonzeption des deutschen Staatssekretärs Carl von Schubert, in: Bohemia 14 (1973) 320-339; hier: 325.

${ }^{66}$ Vgl. Miroslav Houštecký, Plán rakousko-německé celní unie v roce 1931 a postoj Československa [Der Plan der österreichisch-deutschen Zollunion im Jahre 1931 und die Haltung der Tschechoslowakei], in: Československý časopis historický 4 (1956) 27-51.

67 Campbell, Confrontation, 217.

68 In diesem Sinne wirkten sehr breit Theatervorstellungen und Lieder von Jiř́ Voskovec (19051981) und Jan Werich (1905-1980) im Prager Osvobozené divadlo [Befreites Theater].

69 Thomas Storch, Die Beurteilung der nationalsozialistischen "Machtergreifung“ 1933 durch die tschechoslowakische Regierung, in: Bohemia 18 (1977) 290-300; hier: 293. 
Tschechoslowakei an. Alles deutet darauf hin, daß die Prager Regierung an einer Fortsetzung korrekter zwischenstaatlicher Beziehungen zu Deutschland interessiert und zu gewissen Zugeständnissen gegenüber Deutschland bereit war $^{70}$. Das hinderte allerdings die Tschechoslowakische Republik nicht daran, nach dem Januar 1933 ein beispielhaftes Asylland für Tausende von reichsdeutschen Emigranten zu werden. Nicht nur Heinrich Mann und Thomas Mann erhielten das Heimatrecht in einem ostböhmischen Städtchen und somit die tschechoslowakische Staatsbürgerschaft, sondern auch der Parteivorstand der deutschen Sozialdemokratie wirkte fünf Jahre lang in der Tschechoslowakei, desgleichen viele Künstler und Schriftsteller, die die demokratischen Freiheiten des Aufnahmelandes zu schätzen wußten ${ }^{71}$.

Trotz wirtschaftlicher Schwierigkeiten der Krisenjahre war das Verhältnis eines großen Teils der tschechischen Öffentlichkeit zu den reichsdeutschen Emigranten wohlwollend, in vielen Fällen hilfsbereit, wenn auch die größte Hilfe von sudetendeutschen Demokraten kam. Tageszeitungen und Zeitschriften aus dem tschechischen rechtsnationalen Lager entfachten zwar eine Hetzkampagne gegen die reichsdeutsche Emigration, die kein Geld ins Land bringe, sondern nur um Geld bitte ${ }^{72}$, aber im großen und ganzen war die Asylpraxis in der Tschechoslowakei liberaler als in anderen europäischen Staaten ${ }^{73}$. Tschechische Faschisten fanden Worte der Bewunderung für die Ausrottung der Juden, Kommunisten und Sozialdemokraten im nationalsozialistischen Deutschland, obgleich sie vor der deutschen Expansionspolitik auch Angst verspürten. In ähnlicher Weise bezeichnete die oppositionelle Slowakische Volkspartei die Koalitionsregierung in Prag mit Abscheu als eine Regierung der Tschechen und Deutschen und lehnte es ausdrücklich ab, in einer Regierung mit deutschen Ministern zu sitzen ${ }^{74}$. Noch in den letzten Parlamentswahlen vom Mai 1935 zeigte die HlinkaPartei kein Interesse an einer Zusammenarbeit mit den Karpatendeutschen und betonte nach wie vor den angeblich allslawischen Charakter ihrer Politik ${ }^{75}$. Erst während der Zuspitzung der tschechoslowakischen Krise im Jahre 1938 unterstützte wenig-

\footnotetext{
${ }^{70}$ Vgl. Otto Novák, Die Politik der ČSR gegenüber dem Deutschen Reich und den deutschen Demokraten ab 1933, in: München 1938. Das Ende des alten Europa, hrsg. von Peter Glotz, KarlHeinz Pollok, Fürst Karl von Scbwarzenberg und John van Nes Ziegler (Essen 1990) 179-197; hier: 180.

1 Vgl. Drehscheibe Prag. Zur deutschen Emigration in der Tschechoslowakei 1933-1939, hrsg. von Peter Becber und Peter Heumos (Veröffentlichungen des Collegium Carolinum 75, München 1992).

${ }^{72}$ Vojtěch Blodig, Die tschechoslowakischen politischen Parteien und die Unterstützung der deutschen und österreichischen Emigration in den 30er Jahren, in: München 1938, 251-270; hier: 254.

${ }_{73}$ Brigitte Seebacher-Brandt, Die deutsche politische Emigration in der Tschechoslowakei, in: München 1938, 229-249; hier: 230; Werner Röder, Drehscheibe - Kampfposten - Fluchtstation. Deutsche Emigranten in der Tschechoslowakei, in: Drehscheibe Prag, 15-29, hier: 17-18.

74 Deutsche Gesandtschaftsberichte aus Prag. Innenpolitik und Minderheitenprobleme in der Ersten Tschechoslowakischen Republik 4: Vom Vorabend der Machtergreifung in Deutschland bis zum Rücktritt von Präsident Masaryk 1933-1935. Berichte des Gesandten Koch, der Konsuln von Bethusy-Huc, von Druffel, von Pfeil und des Gesandtschaftsrates von Stein, hrsg. von Heidrun und Stepban Dolezel (Veröffentlichungen des Collegium Carolinum 49/IV, München 1991) 66-67, 139.

${ }^{75}$ Ebd. 216.
} 
stens der radikale Flügel der Slowakischen Volkspartei die deutsche nationalsozialistische Propaganda gegen das demokratisch-parlamentarische System der Tschechoslowakischen Republik, wobei besonders die Erfolge Deutschlands bei der Bekämpfung der Kommunisten und Juden hervorgehoben wurden.

Von Ende 1937 an verstärkte sich die nationalsozialistische Propaganda vom Deutschen Reich aus gegen die Tschechoslowakei als Feind Nummer eins ${ }^{76}$. Es zeigte sich immer klarer, daß nicht nationale Probleme, sondern entgegengesetzte politische Prinzipien das Wesen dieser Auseinandersetzung bestimmten. Der größte tschechische Schriftsteller des 20. Jahrhunderts, Karel Capek (1890-1938), beobachtete mit Sorge die Entwicklung im benachbarten Deutschen Reich, besonders nach dem Anschluß Österreichs im März 1938: „Dieser hastige Unifikationsprozeß der deutschen Nation drückt sich mit fataler Notwendigkeit auch darin aus, wie sich die deutsche Nation auf alle erdenkliche Weise, auch in kultureller und moralischer Hinsicht, ,für sich selbst" umgestaltet, wie sie sich nicht nur politisch, sondern auch geistig mit ihrer ,deutschen 'Weltanschauung, ihrer Bildung, ihren Rassenvorurteilen, ihrer Kulturauffassung, nahezu auch mit ihrem deutschen Gott einigt. Mit anderen Worten, im Interesse ihrer nationalen Einheit schließt sie sich bewußt und absichtlich aus der europäischen Gemeinschaft, aus der geistigen Solidarität der europäischen Nationen aus. Sofern sie es innerhalb ihrer Grenzen tut, ist es ihre eigene Sache, obwohl das keinem gleichgültig ist, für den die Menschheit, Humanität und der geistige Fortschritt keine leeren Worte sind; das kann schon deshalb nicht gleichgültig sein, weil das Mitwirken einer so großen Nation an gemeinsamen europäischen Idealen empfindlich fehlt und fehlen wird. (...) Wir können dessen gewiß sein, daß auch die deutsche Nation früher oder später, nach größeren oder kleineren Opfern in die Lage geraten wird, den Weg aus ihrer Isolation und die Rückkehr in die geistige Gemeinschaft Europas zu suchen. Niemand kann sich dauernd und ungestraft aus der Gemeinschaft anderer Nationen ausschließen." ${ }^{\text {"77 }}$

Vom gewaltigen Einigungsprozeß der deutschen Nation wurde auch ein großer Teil der Sudetendeutschen in der Tschechoslowakischen Republik ergriffen, die nun nach der Ansicht Čapeks - ein besonderes deutsches Recht, das Recht auf deutsche nationale Isolation genießen wollten. Das konnte ihnen jedoch nicht eine Nation bieten, deren Vergangenheit, Gegenwart und Zukunft in der europäischen Kooperation fest verankert war. Noch im Spätsommer und Frühherbst 1938 hörte die Mehrheit der tschechischen politischen Parteien und ein Großteil der tschechischen Öffentlichkeit nicht auf, zwischen dem Hitler-Deutschland und dem demokratischen Deutschland zu unterscheiden. Das große Dilemma, das sich aus der Frage ergab, ob die tschechoslowakische Demokratie und Unabhängigkeit gegen die Expansion des Deutschen Reiches mit Waffen verteidigt werden sollte oder nicht, wurde durch die Annahme des Münchner Abkommens zwischen Deutschland, Großbritannien, Frankreich und

\footnotetext{
76 Vgl. Rudolf Jaworski, Die Tschechoslowakei in der NS-Propaganda des Jahres 1938, in: München 1938, 161-178.

77 Karel Čapek, Lekce dějin [Eine Lektion der Geschichte], in: Př́tomnost (Praha), Jg. 15, Nr. 17 vom 27. April 1938, 257; nachgedruckt in: ders., Na břehu dnů [Am Ufer der Tage] (Praha 1966) $398-400$.
} 
Italien am 29. September 1938 zugunsten einer zeitweiligen Vertagung des Krieges und einer politischen Einordnung der Tschechoslowakei in die Großmachtsphäre Deutschlands entschieden. Das Trauma von München 1938 hinterließ tiefe Spuren im Verhältnis der Tschechen zu Deutschland und Westeuropa über zwei oder drei Generationen $\operatorname{lang}^{78}$.

In der tschechischen Politik und im gesamten gesellschaftlichen und kulturellen Leben der Tschechen trat nach dem 29./30. September 1938 eine jahrzehntelang nicht dagewesene Ernüchterung ein. Der neue Prager Außenminister František Chvalkovský (1885-1945), der 1927 bis 1932 als Gesandter in Berlin und 1932 bis 1938 in Rom tätig war, versicherte seinem deutschen Amtskollegen Joachim von Ribbentrop bereits am 13. Oktober 1938, das heißt zwei Wochen nach dem Münchner Abkommen, daß Prag eine enge Zusammenarbeit mit Deutschland anstrebe. An der tschechischen Grenze mit Deutschland sollten keine Befestigungen errichtet werden, die tschechische Armee werde auf ein Minimum reduziert, die politischen Parteien sollten aufgelöst, und auch die Judenfrage müsse geklärt werden. Wirtschaftlich wollte sich die verkleinerte Tschecho-Slowakische Republik dem deutschen Wirtschaftssystem anpassen. Die neue Prager Regierung war sich der erdrückenden geopolitischen Realität in einem Maße bewußt, daß Ministerprāsident Rudolf Beran (1887-1954) erklärte, die Tschecho-Slowakei könne ohne das deutsche Wohlwollen überhaupt nicht existieren $^{79}$. Diese Einstellung gegenüber dem nationalsozialistischen Deutschland, die einer tiefen Enttäuschung über das Verhalten der Westmächte in der Septemberkrise 1938 entsprungen war, beschränkte sich keinesfalls nur auf die tschechische konservative Rechte. Die führende tschechische liberale Tageszeitung Lidové noviny [Volkszeitung] faßte die in der damaligen tschechischen Gesellschaft fast allgemein verbreitete realpolitische Resignation zusammen: „Soll nun die Welt nicht vom Recht, sondern von der Stärke beherrscht werden, muß unser Platz dort sein, wo es größere Stärke und größere Entschlossenheit gibt. Es bleibt uns nichts anderes übrig: suchen wir eine Verständigung mit Deutschland, werden wir zum großen Lieferanten und Abnehmer von ihm, lehnen wir jedwede Kombination ab, die uns in irgendeine Front gegen Deutschland einreihen möchte. “80

Auch einige weltoffene Politiker und Journalisten, die zu den Stützen des demokratisch-parlamentarischen Regimes der Ersten Tschechoslowakischen Republik gehört hatten, erwogen ernsthaft die Möglichkeit, das politische System auf dem böhmischmährischen Restgebiet den reichsdeutschen Vorstellungen anzupassen und die ethnisch-kulturelle Eigenständigkeit der Tschechen der nationalpolitischen Vorherrschaft der Deutschen in Mitteleuropa unterzuordnen ${ }^{81}$. Eine einigermaßen vernünftige, das tschechische Nationalleben im unpolitischen Bereich respektierende reichsdeutsche

78 Zutreffend vgl. Joseph Frederick Zacek, The Czechoslovak View, in: Reappraising the Munich Pact: Continental Perspectives, hrsg. von Maya Latynski (Washington 1992) 47-59, hier: 56.

79 L'ubomír Lipták, Slovensko v 20. storočí [Die Slowakei im 20. Jahrhundert] (Bratislava 1968) 168.

so Lidové noviny (Praha), Jg. 46, Nr. 498 vom 4. Oktober 1938; zit. nach Lipták, Slovensko, 168.

\$1 Als charakteristisches Beispiel kann Ferdinand Peroutka (1895-1978), Begründer und langjähriget Chefredakteur der einflußreichen liberalen Wochenzeitung Přtomnost [Die Gegenwart], angeführt werden. 
Politik hätte die einmalige Gelegenheit gehabt, die große Desillusion der tschechischen Gesellschaft auszunutzen und ein gegenseitiges Vertrauen zwischen Tschechen und Reichsdeutschen langsam anzubahnen. Grundsätzlich änderte daran nicht viel die Errichtung des Protektorates Böhmen und Mähren am 15./16. März 1939. Als im Dezember 1939 der Vorsitzende der Protektoratsregierung, Alois Eliáš (1890-1942), im Interview für das offizielle Deutsche Nachrichten-Büro zu einem gesunden Wettbewerb des tschechischen Volkes mit dem deutschen Volke und zu einem harmonischen Zusammenleben der beiden Völker in Mitteleuropa aufforderte ${ }^{82}$, lehnte er damit ein auf Ungleichheit und Unterwürfigkeit gegründetes Verhältnis der Tschechen zu den Deutschen ab. Die deutsche Okkupationspolitik im Protektorat Böhmen und Mähren vereinte jedoch das Interesse an der Erhöhung der Wirtschaftskraft der böhmischen Länder mit einer rücksichtslosen Unterdrückung der tschechischen Hochschulen und der unabhängigen tschechischen Bildungsschicht, so daß sich die Perspektive einer Vernichtung der tschechischen nationalen Existenz eröffnete ${ }^{83}$.

Für die von Edvard Beneš geführte tschechische Emigration im Westen war das deutsche Problem in erster Linie mit dem Scheitern des Minderheitenschutzes in der Zwischenkriegszeit verbunden, wobei zunächst territoriale Veränderungen neben Bevölkerungsverschiebungen erwogen wurden. Das Nachkriegs-Deutschland stellte sich Beneš im November 1941 als eine dezentralisierte Konföderation vor, in der die Vorherrschaft Preußens über andere Stämme der deutschen Nation gebrochen sein würde ${ }^{84}$. Britische Kommentare stellten fest, daß die Vorstellungen des tschechoslowakischen Exils konzilianter als die Vorschläge der polnischen Regierung oder der Sowjetführung waren ${ }^{85}$. Im Londoner Außenministerium und im britischen Unterhaus wurde mit Verstimmung zur Kenntnis genommen, daß Beneš die Grenzen des Deutschen Reiches auf den Stand von vor 1938 zurückversetzen wollte, nur mit kleineren Korrekturen zugunsten der Nachbarn, aber das sollte keine Verkleinerung Deutschlands bedeuten, weil etwaige territoriale Verluste durch den Erwerb einiger außereuropäischer Kolonien hätten kompensiert werden können ${ }^{86}$. Interessant war auch die Mitteilung des amerikanischen Staatssekretärs Sumner Welles im Unteraus-

${ }^{82}$ Dokumenty z historie československé politiky 1939-1943, 2: Spolupráce československé emigrace na západě $s$ domácím odbojem, její vztah $\mathrm{k}$ tzv. protektorátní vládě a germanizační politika okupantů [Dokumente aus der Geschichte der tschechoslowakischen Politik 1939-1943, 2: Die Zusammenarbeit der tschechoslowakischen Emigranten im Westen mit dem Widerstand in der Heimat, deren Beziehung zur sogenannten Protektoratsregierung und die Germanisierungspolitik der Okkupanten], hrsg. von Libuše Otáhalová und Milada Červinková (Acta Occupationis Bohemiae et Moraviae 2, Praha 1966) 493-494.

${ }^{83}$ Vgl. Detlef Brandes, Die Tschechen unter deutschem Protektorat, 1: Besatzungspolitik, Kollaboration und Widerstand im Protektorat Böhmen und Mähren bis Heydrichs Tod 1939-1942 (München, Wien 1969); 2: Besatzungspolitik, Kollaboration und Widerstand im Protektorat Böhmen und Mähren von Heydrichs Tod bis zum Prager Aufstand 1942-1945 (München, Wien 1975).

${ }^{81}$ Dokumente zur Deutschlandpolitik 1/1:3. September 1939 bis 31. Dezember 1941. Britische Deutschlandpolitik, bearb. von Rainer A. Blasius (Frankfurt am Main 1984) 539.

${ }^{85}$ Dokumente zur Deutschlandpolitik I/3: 1. Januar bis 31. Dezember 1942. Britische Deutschlandpolitik, bearb. von Rainer A. Blasius (Frankfurt am Main 1988) 1003.

${ }^{86}$ Ebd. I/1, 579-580, 587-589. 
schuß des Kongresses der Vereinigten Staaten im Januar 1943, derzufolge Beneš die Sowjetführung vor einer Unterstützung des Kommunismus in Deutschland am Ende des Krieges gewarnt hatte, weil ein kommunistisches Deutschland angeblich viel stärker die alldeutschen Ziele (Pan German aims) verfolgen würde als ein liberal-religiöses Regime $^{87}$. Die spätere Koordinierung der tschechoslowakischen Außenpolitik mit Moskau bedeutete dann einen weitgehenden Verzicht auf eine selbständige Politik gegenüber Deutschland.

Für die autonome und vom 14. März 1939 an unabhängige Slowakei war das Deutsche Reich die einzige Schutzmacht der staatlichen Selbständigkeit, wenn auch die Souveränität der Slowakischen Republik beschränkt war. Staatspräsident Jozef Tiso (1887-1947) und seine Minister wetteiferten mit der ungarischen Regierung um die Gunst des mächtigen Deutschen Reiches und um eine privilegierte Stellung im „neuen Europa“ Adolf Hitlers. Die Reichsdeutschen erfreuten sich keiner besonderen Sympathien bei den Slowaken, nicht zuletzt wegen deutscher Eingriffe in das slowakische Wirtschaftsleben ${ }^{88}$. Mehr oder weniger freiwillig paßte die slowakische Staatsführung die innere und auswärtige Politik der Slowakei dem Vorbild des nationalsozialistischen Deutschland an, was sich in der Einführung des Führerprinzips und in der Liquidation der politischen Opposition, in der Teilnahme der slowakischen Armee an den Feldzügen gegen Polen und die Sowjetunion und in der planmäßigen Liquidierung der meisten slowakischen Juden ausdrückte. Der organisierte Widerstand, der im Slowakischen Nationalaufstand von Ende August bis Ende Oktober 1944 seinen Höhepunkt fand, war eindeutig gegen die deutschen Okkupanten und ihre Handlanger gerichtet.

Sowohl in den böhmischen Ländern als auch in der Slowakei wurde in den letzten Monaten des Zweiten Weltkrieges immer weniger zwischen den Reichsdeutschen, den Sudetendeutschen und den Karpatendeutschen unterschieden; nur die Österreicher hatten vielleicht einen etwas besseren Ruf. Sie alle waren Nĕmci [Deutsche], die Feinde, denen man eine Kollektivschuld am Zweiten Weltkrieg und an den unermeßlichen Leiden zuschrieb. Nachrichten aus den Konzentrationslagern und grauenvolle Todestransporte von Kriegsgefangenen und Häftlingen über mährische und böhmische Gebiete trugen darüber hinaus zu einer weiteren Verschlechterung des Deutschenbildes unter den Tschechen und Slowaken bei. Das tschechisch-deutsche Verhältnis geriet mit dem Ende des Deutschen Reiches im Mai 1945 an den tiefsten Punkt seiner jahrhundertelangen Geschichte. Kaum jemand von den im Jahre 1945 lebenden Tschechen und Slowaken konnte an die Möglichkeit eines wirtschaftlichen und demokratischen Wiederaufbaues Deutschlands innerhalb einer relativ kurzen Zeit glauben.

${ }^{87}$ Dokumente zur Deutschlandpolitik I/4: 1. Januar bis 31. Dezember 1943. Amerikanische Deutschlandpolitik, bearb. von Marie-Luise Goldbacb (Frankfurt am Main 1991) 71.

${ }^{88}$ Lipták, Slovensko, 194-205. 
